\title{
O DIRIGISMO LAICO: D. PEDRO II E O PROJETO IMPERIAL
}

Afrânio Biscardi

\section{Resumo}

Este estudo traça um breve esboço sobre a maneira pela qual a historiografia trata o mecenato artístico de D. Pedro II, sua relação com os projetos construtores da incipiente nação e a imagem criada do próprio monarca. Considera ainda a ruptura do academismo romântico face aos padrões neoclássicos nas artes plásticas.

Palavras-chave: Mecenato, dirigismo artístico, neoclássico, romantismo.

\begin{abstract}
This estudy draws a sketch about the way historiography treats the artistic patronage of $\mathrm{D}$. Pedro II, its relation with the constructor projects of the incipient nation as well as with the image of the monarch. And also how the rupture of the romantic academicism face to the neoclassic patterns in plastic arts is treated.
\end{abstract}

Keywords: Patronage, neoclassic, romanticism.

D. Pedro II, além de carismático estadista, revelou-se um mecenas da produção artística e literária no Brasil. O bolsinho do imperador patrocinou diversos literatos, artistas e profissionais de vários ramos da ciência, no intuito de favorecer uma fundamentação e autonomia cultural necessária à elite local, ansiosa em definir sua própria identidade. Para o jovem monarca, a unificação territorial do império podia ser insuflada pela unicidade cultural, já que a carência de uma identidade verdadeiramente nacional poderia resultar, a médio ou longo prazo, em agente de divisão interna ou de enfraquecimento das instituições do governo; o que repercutiu na necessidade de se adotar uma produção artística de temática autóctone, que realçasse as potencialidades naturais do país, o índio como habitante genuíno e elemento da brasilidade, e os temas históricos nacionais.

Lilia Moritz Schwarcz, no hodierno "As Barbas do Imperador", ressalta que a assídua participação do imperador no Instituto Histórico e Geográfico Brasileiro (criado em 1838) e seu mecenato fizeram do romantismo um projeto oficial. Os trabalhos do IHGB circunscreveram-se nos moldes deste projeto propício ao fortalecimento da monarquia, do Estado e da unidade territorial, que seria também cultural. Nos recintos do IHGB foram constantes as discussões a respeito da importância dos reis para a conformação da cultura nacional, assim como as comparações de D. Pedro II com reis antigos, como Alexandre, Augusto, Marco Aurélio, entre outros, e os mais próximos cronologicamente, como o Luís XIV, rei da França de 1643 a 1715, cujo exemplo era seguido pelo nosso príncipe. Ainda de acordo com a autora, a produção intelectual do império se voltou para as originalidades locais e foi repleta de noções como autonomia e patriotismo, conferindo destaque ao índio e à exuberante natureza brasileira. Os poemas indianistas foram acrescidos de termos indígenas por meio dos dicionários de línguas nativas organizados pelos jesuítas. O imperador, bastante interessado em estudos de lingüística e etnografia americanas, buscou aprender o tupi e o guarani - o que lhe ajudaria

1 SCHWARCZ, Lilia M. "Um monarca nos trópicos": O Instituto Histórico e Geográfico Brasileiro, a Academia Imperial de Belas-Artes e o Colégio Pedro II. In: As Barbas do Imperador: D. Pedro II, um monarca nos trópicos. São Paulo: Companhia das Letras, 1998. p. 125-157. 
nos embates com o Paraguai - e propôs a edição e circulação de dicionários e gramáticas destes idiomas.

"A ciência sou eu". Schwarcz frisa esta célebre frase proferida por D. Pedro II no IHGB, a qual nos remete ao dito Luís XIV, também empreendedor de um projeto cultural que o permitiria alcançar todo o Império, a quem é atribuída a famosa sentença: "L'État c'est moi" - O Estado sou eu. Segundo a autora, o monarca patrocinou particularmente as pesquisas relevantes à história do Brasil e contribuiu de diversos modos com o trabalho de naturalistas, dentre os quais Couty, Emílio Goeldi e Agassiz. O mesmo se deu com os geólogos O. Derby e Charles Frederick Hartt, comandantes da Comissão Geológica do Império, responsável pela coleta de 500 mil amostras de rochas para análise e catalogação. Auxiliou também o botânico Glauziou e o cartógrafo Seybold, além de vários advogados, agrônomos, arquitetos, professores, engenheiros, médicos, farmacêuticos, militares, músicos, padres e pintores. Ou seja, financiou o avanço dos diversos ramos do conhecimento, dado seu fascínio pelas ciências, pelas letras e as artes.

É neste ínterim que a Academia Imperial de Belas-Artes ganhou impulso e, sob a égide da laica estética neoclássica, recebeu vasto volume de encomendas de pinturas oficiais do império, sobretudo retratos do mecenas e cenas de exaltação cívica do Brasil, objetivando representar a nação da mesma maneira que a literatura do IHGB o fizera. O imperador, entre 1842 e 1844, instituiu prêmios para os trabalhos de destaque no IHGB, o que também ocorreu na Academia de Belas Artes. Em 1845, é lançado o prêmio de viagem à Europa, em que o bolsista permaneceria durante três anos sob orientação de renomados mestres italianos e sobretudo franceses. Em suma, Schwarcz correlata o mecenato de D. Pedro II ao projeto imperial, à ânsia do monarca em não só arraigar a própria imagem de governante comprometido com a nação liberta do colonialismo lusitano, como também fazer sobressair uma memória e perfilhar uma cultura por meio de um projeto maior. Segundo ela, o romantismo brasileiro inseriu-se em um plano político de cunho nacionalista, e não apenas em um movimento estético. De perfil eminentemente estratégico, encarregou-se de fazer as pazes com o indígena pelo passado de barbárie e intolerância, que ora comportava uma leitura honrosa.

A historiadora enfatiza a intrínseca associação entre progresso e intelecto feita pelo imperador, que mantinha no palácio uma biblioteca, um museu, um laboratório e um observatório astronômico. $\mathrm{O}$ apreço do monarca pela erudição muitas vezes o afastava da política, que lhe parecia tediosa. Tanto é que veio presidir 506 sessões do IHGB, enquanto apareceu esporadicamente na Câmara. Schwarcz relata a relação causal do patronato artístico na construção da imagem atribuída a D. Pedro II de sábio governador nos trópicos, protetor das artes e das ciências, um ilustre e inigualável mecenas. No entanto, não se posiciona a respeito destas projeções imagéticas, seja enaltecendo-as, seja questionando-as, o que não ocorreu com muitos autores.

José Maria dos Reis Júnior, autor do clássico "História da Pintura no Brasil", editado na década de 1940, considera o segundo reinado um período de notável estabilidade política e econômica, responsável pelo desenvolvimento cultural da época. A independência foi um fator de coesão social, uma vez que sociedade como um todo sentia ojeriza pelos portugueses e tudo que a remetesse ao colonialismo, de forma que o país começava a emancipar-se política e espiritualmente. O autor frisa a importância do esforço pessoal do imperador para a gênese deste período de esplendor, quando desponta no brasileiro um valor de expressão individual e coletiva: "Sobretudo as letras e as artes

2 JÚNIOR, José Maria dos Reis. História da Pintura no Brasil. São Paulo: Editora “Leia”, 1944. 
mereceram-lhe sempre atenção carinhosa e pródiga. Colocava-as em tal proeminência, cercava-as de tamanha consideração, que lhes criava um ambiente excepcional, explicativo do surto magnífico que apresentaram ${ }^{3 \prime \prime}$.

Reis Júnior recorre ao juízo feito pelo historiador Argeu Guimarães acerca do estímulo do imperador às artes, com o qual manifesta-se de acordo: "aos três fatores com que Taine explica as florações artísticas fôra mister ajuntar um quarto no Brasil: D. Pedro II" " . O fulcro da crítica do autor é reconhecer o mérito do monarca em estimular com afinco e ensejar condições de desenvolvimento à inteligência artística latente dos brasileiros, outrora entravada pelo obscurantismo colonial. No entanto, não se aventura na descrição quantitativa das importâncias investidas no empreendimento de tamanha envergadura. $\mathrm{O}$ material intitulado "Arte no Brasil", da editora Nova Cultural, ressalta que para o país alcançar o grau de desenvolvimento artístico e cultural verificado nas décadas de 60 e 70 do oitocentos, fora de suma importância o empenho pessoal do imperador, "cuja atuação em prol das artes, das letras e das ciências fora incansável"’.

O crítico e historiador da arte Quirino Campofiorito, na "História da Pintura Brasileira no Século XIX", coleção de sua autoria, aborda sucintamente o mecenato no volume "A Proteção do Imperador e os Pintores do Segundo Reinado", reconhecendo o exclusivo papel do poder imperial em oferecer a oportunidade de aprimoramento artístico no exterior por meio da concessão das bolsas de estudos, muitas vezes pagas pelas economias particulares de D. Pedro II. Descreve a benevolente proteção conferida aos artistas pelo monarca como imbuída de uma mentalidade elitista presa aos modelos das cortes, de maneira a não valorizar quaisquer traços populares ou nativistas. O dirigismo acadêmico, caracterizado pelo autor como "modernismo laico e progressista, mas imposto de fora", teria interrompido a incipiente inventividade dos pintores do barroco colonial em algumas regiões, incutindo nas artes plásticas os cânones austeros academizados que caracterizariam a pintura oitocentista.

Durante todo o século XIX a pintura não se esquivou muito dos padrões neoclássicos ou, conforme a definição de Quirino, da linha acadêmico-neoclassicista, uma vez que havia entraves à entrada de novas temáticas e inovações formais. No entanto, a preferência na pintura pelos motivos nobres mitológicos, históricos e retratos foi se abrandando, segundo Campofiorito, e abrindo lugar para uma temática mais legítima, de conceitualização vulgarizada, ainda que com considerável timidez. De acordo com o crítico, houve o prolongamento através de todo o século XIX de "uma contenção acadêmica da fatura pictórica e de um insípido convencionalismo temático, [que] nos afastou indiscutivelmente dos estimulantes debates que acompanharam na Europa as sucessivas oposições entre neoclássicos, românticos, realistas e impressionistas" ${ }^{8}$. Havia um papel intermediador do dirigismo artístico imperial, manifestado através de um entrave às manifestações que fizessem rupturas abruptas com o neoclassicismo cortesão.

O capítulo bastante didático da professora Sonia Gomes Pereira, intitulado "Arte no Brasil no Século XIX", integrante do livro "História da Arte no Brasil / Textos de

\footnotetext{
${ }^{3}$ JÚNIOR, José Maria dos Reis. op.cit. p. 30

4 ARGEU GUIMARÃES. História das artes plásticas no Brasil. Revista do Instituto Histórico e Geográfico Brasileiro. Rio, 1930. v. IX.

${ }^{5}$ Arte no Brasil. São Paulo: Editora Nova Cultural, 1986.

${ }^{6}$ Arte no Brasil. op. cit. p. 175

7 CAMPOFIORITO, Quirino. História da Pintura Brasileira no Século XIX. Rio de Janeiro: Edições Pinakotheke, 1983.

${ }^{8}$ CAMPOFIORITO, Quirino. op. cit. p. 14.
} 
Síntese" ", trata da seguinte maneira a questão da ruptura do romantismo em relação ao neoclassicismo no Brasil:

Temos hoje consciência de que a produção acadêmica ao longo do século XIX partiu de uma postura inicialmente neoclássica, mas posteriormente acabou por absorver idéias e valores de movimentos posteriores, como o Romantismo, o Realismo, o Impressionismo e o Simbolismo, expurgando destas linguagens os elementos mais audaciosos e preservando sempre o caráter normativo, próprio do sistema acadêmico, ancorado na exigência de um desenho rigoroso e de uma técnica primorosa ${ }^{10}$.

O romantismo brasileiro, conforme aponta Mário Barata no capítulo "A Arte no Século XIX: do Neoclassicismo e Romantismo até o Ecletismo", do clássico "História Geral da Arte no Brasil"", de Walter Zanini, enquadrou-se no que os estudiosos europeus denominaram "romantismo acadêmico", já que "certo convencionalismo dominava as soluções estéticas, compositivas e cromáticas, das obras" 12 . Consoante o autor, a pintura romântica desviava dos padrões neoclássicos no tratamento diverso e diferenciado da cor, e na multiplicidade de gestos. Ao analisar formalmente as pinturas históricas de Vítor Meireles e Pedro Américo referentes à Guerra do Paraguai, Barata situa estas obras no romantismo acadêmico e não no neoclássico.

Se Schwarcz trabalha o romantismo como a mola propulsora de um projeto cultural que visava a consolidação do Império, pode parecer contraditório que o dirigismo exercido pela academia inibisse sua expressão nas artes plásticas. A explicação adquire plausibilidade ao se ater à feição palaciana do movimento no Brasil. Produzido por e para uma elite local, que buscava emancipar-se culturalmente, o romantismo brasileiro foi desprovido da essência revolucionária e militante do modelo francês, conforme explica a autora. Embora partisse do tema nacional, foi uma cultura moldada de acordo com a ótica do escol e, por isso, permeada pela idealização, sem repercussão popular e desprovida dos traços nativistas que poderiam caracterizá-la. Não é de se espantar que o índio idealizado assumisse, nesse caso, não só uma dimensão ética que remonta à endeusada razão francesa, dotado de virtudes e exemplaridade, como também uma estética classicizante, com o corpo modelado nos atletas gregos e a pele esbranquiçada.

As convenções neoclássicas persistentes nas telas românticas impossibilitaram a expressão fidedigna da multifacetada realidade brasileira, resultando numa produção artística distante do nosso universo e suas possibilidades de representação. Isto explica a irrisória verossimilhança com que o negro foi tratado na pintura, uma vez que os raríssimos negros nas telas eram semelhantes aos escravos gregos, seus traços foram relegados em função da ótica idealizadora. De acordo com o crítico de arte Carlos Cavalcanti, no texto "O Predomínio do Academismo Neoclássico",", publicado em fins da década de 1960, o jovem aluno da Academia Imperial de Belas Artes João Maximiano Mafra propôs a

\footnotetext{
9 OLIVEIRA, Myrian Andrade Ribeiro de (Org.). História da Arte no Brasil / Textos de Síntese. Rio de Janeiro. Universidade Federal do Rio de Janeiro.

10 PEREIRA, Sonia Gomes. Arte no Brasil no Século XIX. In: OLIVEIRA, Myrian Andrade Ribeiro de (Org.). op. cit. p. 55.

11 ZANINI, Walter (Org.). História Geral da Arte no Brasil. São Paulo: Instituto Walther Moreira Salles, 1983. 2 v.

12 BARATA, Mário. A Arte no Século XIX: do Neoclassicismo e Romantismo até o Ecletismo. In: ZANINI, Walter (Org.). op. cit. p. 420.

${ }^{13}$ CAVALCANTI, Carlos. O Predomínio do Academismo Neoclássico. In: PONTUAL, Roberto. Dicionário de Artes Plásticas no Brasil. Rio de Janeiro: Civilização Brasileira, 1969.
} 
substituição dos modelos brasileiros, feios e desproporcionados, por europeus imigrantes, de beleza consonante com a estética em apreço. Cavalcanti atribui a aversão ao negro não apenas a um preconceito estético, mas também ao interesse da classe dominante, a burguesia da segunda metade do século XIX, em ocultar as mazelas da escravidão, da mesma forma que o academicismo europeu evitava representar o proletariado cuja situação se agravara após a Revolução Industrial.

A especificidade do academismo neoclássico não concerniu propriamente à sua estética, e sim ao bom exemplo que é de arte dirigida da modernidade - esta é a hipótese central do artigo supracitado. E a arte dirigida, em todas as épocas, se encarrega de fazer valer os interesses da classe dominante, política e economicamente. Ainda na ótica do autor, o dirigismo sofreu vicissitudes no decorrer da história, visando adaptar-se a novas condições sociais sem, contudo, ter desaparecido. No texto é traçada a trajetória da adequação da orientação artística, em sua forma e conteúdo, à inteligência das épocas até chegar ao cenário revolucionário da burguesia francesa no século XVIII. Com a ascensão da burguesia mercantil na Renascença, os valores cientificistas e racionalistas impregnaram as artes e, concordantes com o laicismo e pragmatismo burgueses, nas palavras do autor, estabeleceram a transmigração do foco dos temas místicos e teológicos para os conceitos filosóficos e estéticos em voga. $\mathrm{O}$ artesão não era mais vinculado à oficina do templo, e sim à academia oficial e secularizada, onde recebia uma orientação teorética e estilística bastante direcionada.

No cenário da Revolução Francesa, o neoclassicismo ou academismo ${ }^{14}$ foi adotado como o estilo oficial. O dirigismo artístico revelou-se então eficaz em limitar a criatividade do artista através do restringimento do repertório temático que, além de alienar leitura do artífice da vida social que lhe é contemporânea (a invocação do passado se sobrepõe à interpretação crítica e realista da atualidade), o levou a distanciar-se da realidade presente, dada sua imperfeição tão dissonante do belo idealizado sugerido pelos gregos e os renascentistas. As ligaduras das colocações agora esboçadas com o projeto imperial trabalhado por Schwarcz ganham precisão, uma vez que fundamentam a circunscrição do academismo romântico, como arte direcionada, à servência aos interesses da governança monárquica no Brasil.

A carência de unidade cultural já era entendida como possível fator de divisão geográfica pelos predecessores do monarca. D. Pedro I apressou a criação das faculdades de direito em Olinda e São Paulo, em 1827, e reformulou as escolas de medicina em 1830. A vinda da família real para o Rio de Janeiro abriu novos horizontes para a vida do país. Muitas medidas administrativas tomadas por D. João VI visavam lançar as bases para uma grande transformação política, econômica e cultural que permitisse à tímida cidade se consolidar como a sede do vasto império português e se integrar à dinâmica do capitalismo europeu - houve a revogação do Pacto Colonial e a Abertura dos Portos. Outro feito joanino de grande relevância é a contratação da Missão Artística Francesa, composta por mestres e artistas marcadamente neoclássicos, para dar uma guinada na produção artística

\footnotetext{
14 Sinonímia apresentada pelo autor, à qual Sônia Gomes Pereira faz algumas observações, de acordo com a citação que segue: "Não se deve tomar o conceito de acadêmico como sinônimo de neoclássico, como ocorreu freqüentemente na historiografia da arte brasileira". Daí segue a citação da autora feita na pág. 5, que trata da postura inicialmente neoclássica posteriormente acrescida de elementos característicos de movimentos posteriores, como o romantismo. PEREIRA, Sonia Gomes. Arte no Brasil no Século XIX. In: OLIVEIRA, Myrian Andrade Ribeiro de (Org.). op. cit. p. 55.
} 
colonial e instituir o ensino oficial de artes no país que agora adentrara no formato do século das luzes.

É com D. Pedro II que o projeto de eqüipolência artística do império às nações européias tomou maior vulto, devido aos auxílios financeiros. Cavalcanti e outros autores situam o apogeu do neoclassicismo na segunda metade do XIX, quando artistas nacionais educados pelos artistas franceses despontaram com brilhantismo no cenário das artes plásticas. $\mathrm{O}$ autor concebe ainda nesta culminância neoclássica a introdução das vertentes românticas e realistas nas obras que iam libertando-se paulatinamente dos temas consagrados pela estética neoclássica - alegóricos, greco-romanos e das Sagradas Escrituras, entre outros - para absorver temáticas nacionais, históricas e contemporâneas. Não obstante tenha havido entradas para a brasilidade e a subjetividade do artista (verificada sobretudo nas duas últimas décadas do oitocentos), o sentimento, na afirmação de Cavalcanti, continuou europeu, pois ainda era regido por convenções neoclássicas de forma e cor.

Por fim, Cavalcanti associa a "diluição do dogmatismo neoclássico e sua transformação em academismo eclético eivado de tendências românticas e realistas" à incipiente industrialização do país. O panteão grego foi sobreposto por homens de pioneirismo memorável no processo industrial brasileiro, como Mauá e Delmiro Gouveia. Entretanto, essa diluição foi parcial, pois na fatura artística houve continuidade das prescrições neoclássicas. No caso europeu, a estética neoclássica oficial admitia a agregação de alguns elementos do romantismo e do realismo, contanto que sua ousadia não pendesse para a interpretação dos problemas sociais existentes. Por isso o autor descreve a rejeição exercida pela estética oficial em relação ao romantismo insurgente e autêntico de Delacroix, como também no tocante ao realismo de Coubert. Conforme Quirino Campofiorito, os alunos contemplados pela bolsa de estudos no exterior recebiam influências européias na aspiração por temas e aspectos formais fugidios ao neoclassicismo. Todavia, a vinculação dos bolsistas ao dirigismo imperial os levou a não trilhar com afinco os caminhos românticos e realistas que estavam sendo abertos na Europa. Deveriam inibir suas tendências a enveredar-se pelos movimentos rebeldes à estética oficial que estavam se consolidando no cerne europeu, uma vez que o imperador mecenas lhes concedera um auxílio financeiro que os tornara dependentes do viés artístico da academia, ancorado na estética oficial francesa.

Vale, por último, esboçar considerações ao patronato artístico de D. Pedro II feitas por José Carlos Durand, no livro "Arte, Privilégio e Distinção"15, as quais descrevem um monarca um tanto parco e rigoroso na concessão de benefícios. O autor salienta, por meio da citação de um trecho de Guilherme Auler, que o governador era bastante metódico e cauteloso em relação aos auxílios distribuídos:

(...) recebendo um pedido ou requerimento de auxílio para estudar, D. Pedro II ordena uma espécie de sindicância, primeiramente, para informar-se sobre o suplicante. Depois, indaga qual a quantia necessária. Em seguida, lavra-se o decreto ou portaria e, em casos raros, transmite ordem por ofício. O estudante contemplado com a mesada imperial é obrigado a apresentar trimestralmente certificados de aproveitamento, freqüência e boa conduta, e, na hipótese de acharse no estrangeiro, assume o compromisso de, findos os estudos, regressar ao

15 DURAND, José Carlos. Arte, Privilégio e Distinção: artes plásticas, arquitetura e classe dirigente no Brasil, 1855/1985. São Paulo: Perspectiva: Editora da Universidade de São Paulo, 1989. 
Brasil, para aqui disseminar os conhecimentos adquiridos por generosidade do monarca"16.

O ponto crucial da crítica de Durand é atacar os autores que enalteciam o mecenato de D. Pedro II ao ponto de insinuar um sacrifício pessoal do monarca na manutenção dos bolsistas, devido ao seu amor incondicional pelo conhecimento. E a ofensiva parte da comprovação de que as despesas com o número nada surpreendente de contemplados eram pequenas, pois estavam na cifra dos cinqüenta contos de réis, o que inclui as aposentadorias, num orçamento total de oitocentos e vinte contos de réis, de acordo com o balancete feito por Auler. Ou seja, os vultosos gastos com a ciência e as artes somavam apenas seis por cento do dispêndio da casa imperial, de onde saíam os recursos do padroado artístico. O que equivale a importância destinada ao verão da família real em Petrópolis, e menos da metade dos custos com as estrebarias do palácio. Ainda segundo Durand, os bolsistas no exterior não representavam nem meio por cento do orçamento controlado pelo imperador.

Ora dotado de um bolso pequenino (um verdadeiro bolsinho do imperador), ora portador de um bolso tão provedor, o monarca dividiu as opiniões dos historiadores quanto ao seu projeto cultural. Contudo, é inegável sua notoriedade ao estimular as artes neste país, seu olhar vivo para o que a ciência e as artes lograriam ao desenvolvimento humano do reino. Se o impulso artístico não teve o fomento esperado e glorificado por muitos, trouxe contribuições ao seu modo para o período em questão. Uma vez que não havia mercado consumidor para as artes plásticas na sociedade brasileira da época, tratouse de oportunidade única de desenvolvimento de artístico para jovens no anonimato, muitos na pobreza. As generalizações encontradas nos materiais consultados não permitem avanços significativos no campo do mecenato. Com exceções no que se refere ao trabalho de Auler, os autores arrolados não nos trazem informações mais específicas como quanto, quando, como e onde o estado fez os investimentos. Tampouco analisaram cada caso, o que os levaria a relativizar os juízos. Esta superficialidade está no que a historiografia da arte brasileira, muitas vezes desinteressada em relação ao século XIX, nos legou.

16 AULER, Guilherme. Os Bolsistas do Imperador. Cadernos do Corgo Seco, Tribuna de Petrópolis, 1956. p.12. 